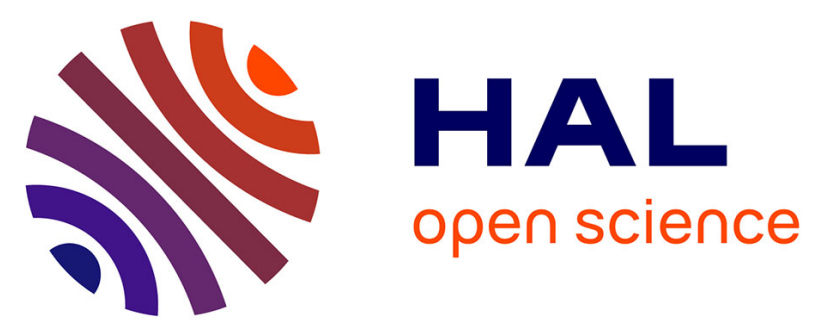

\title{
Impact of water application conditions on nitrogen leaching under furrow irrigation: Experimental and modelling approaches
}

\author{
J.C. Mailhol, D. Crevoisier, K. Triki
}

\section{- To cite this version:}

J.C. Mailhol, D. Crevoisier, K. Triki. Impact of water application conditions on nitrogen leaching under furrow irrigation: Experimental and modelling approaches. Agricultural Water Management, 2007, 87 (3), p. 275 - p. 284. 10.1016/j.agwat.2006.07.015 . hal-00452216

\author{
HAL Id: hal-00452216 \\ https://hal.science/hal-00452216
}

Submitted on 1 Feb 2010

HAL is a multi-disciplinary open access archive for the deposit and dissemination of scientific research documents, whether they are published or not. The documents may come from teaching and research institutions in France or abroad, or from public or private research centers.
L'archive ouverte pluridisciplinaire HAL, est destinée au dépôt et à la diffusion de documents scientifiques de niveau recherche, publiés ou non, émanant des établissements d'enseignement et de recherche français ou étrangers, des laboratoires publics ou privés. 


\title{
Impact of water application conditions on nitrogen leaching under furrow irrigation: Experimental and modelling approaches
}

\author{
J.C. Mailhol, D. Crevoisier and K. Triki \\ Cemagref, French Institute of Agricultural and Environmental Research (Irrigation Division - \\ UR IRMO), UMR G-EAU, 361 rue J.F. Breton, BP 5095, F34033 Montpellier, France
}

\begin{abstract}
Local infiltration tests on $1.5 \mathrm{~m}$ long blocked furrows were carried out on a loam soil to assess $\mathrm{N}$ fertiliser leaching under furrow irrigation where ridging operations entails placing nitrogen on the upper part of the ridge. This article focuses on the impact of flow depths, or water application depth (WAD), on nitrogen movement in seven 1.5-m long blocked furrows. For a first irrigation event, a WAD greater than or equal to $240 \mathrm{~mm}$, significantly reduced the heterogeneity of the $\mathrm{N}$ concentration profiles measured at the top of the ridge and beneath the furrow. The virtually homogeneous $\mathrm{N}$ soil distribution with depth permitted the determination of the nitrogen balance throughout the season using soil samples obtained at the beginning and end of the season as well as the determination of nitrogen present in the crop tissue. This is not possible when there is a heterogeneous $\mathrm{N}$ soil profile at the end of the irrigation season, as observed under moderate WAD conditions. In addition, a substantial WAD delivered during the first irrigation event, and at a period where the plant $\mathrm{N}$ requirements are high, does not affect crop yield potential.
\end{abstract}

A modelling approach, adapted to 2D water and solute transfer, allowed us to validate the estimated $\mathrm{N}$ leaching resulting from $\mathrm{N}$ balance performed under high WAD conditions. About $22 \mathrm{~kg} / \mathrm{ha}$ of $\mathrm{N}$ was leached behind the root zone (around 10\% of the nitrogen application) during the irrigation season under high WAD $(240 \mathrm{~mm}$ during first irrigation and around $200 \mathrm{~mm}$ for the following irrigation events). Modelling should be used to estimate $\mathrm{N}$ leaching under low or moderate WAD conditions because of the heterogeneous $\mathrm{N}$ distribution within the root zone.

Keywords: Furrow irrigation; Infiltration tests; Nitrogen leaching; Nitrogen use efficiency

\section{Introduction}

Although furrow irrigation techniques have been improved, high irrigation rates under furrow irrigation, coupled with substantial field $\mathrm{N}$ fertilisation in some countries (Fernandez et al., 1994 ) has lead to increased risks of groundwater pollution. This situation has incited research on the risks of $\mathrm{N}$ leaching associated with different irrigation and fertilisation practices. Better fertiliser placement, combined with appropriate irrigation management can reduce $\mathrm{NO}_{3}-\mathrm{N}$ leaching according to Robbins and Carter (1980). Recent published works lend credence to this assessment. 
Benjamin et al. (1998) analysed the impact of fertiliser placement for alternate and everyfurrow irrigation systems over two irrigation seasons. The study shows that placing fertiliser in the non-irrigated furrow of an alternate-furrow irrigation system, or placing fertiliser in the row, with either alternate or every-furrow irrigation, could decrease fertiliser leaching without reducing crop production. The results of this work show that there is an increase in $\mathrm{N}$ use efficiency using these techniques when compared with the broadcasting methods. Popova et al. (2000) carried out similar field tests using lysimeters $\left(10 \mathrm{~m}^{2}\right.$ area on $2 \mathrm{~m}$ depth) installed on a chromic luvisol under corn. The $\mathrm{N}$ leaching resulting from two fertilisation/watered methods was quantified during both irrigation and the inter-cropping season. For moderate irrigation rates (120 mm in two applications) and rainfall amounts of $360 \mathrm{~mm}$, the measured $\mathrm{N}$ leaching was $7 \%$ of the $200 \mathrm{~kg} / \mathrm{ha}$ applied, for combined lysimeter results, and $11 \%$ of the $400 \mathrm{~kg} / \mathrm{ha} \mathrm{N}$ for the lysimeter when all the furrows were fertilised/irrigated. No significant yield differences were observed between the treatments attesting that the $\mathrm{N}$ amount has to take into account plant requirements and initial N soil conditions. Lehrsch et al. (2000) also analysed the impact of fertiliser placement (urea) using banding and side-dressing methods while applying water to the same furrow throughout the season and alternating furrows for every second irrigation treatment on a silt loam soil. Banding $N$ on one side of a row rather than broadcasting it, and applying water throughout the season to the same furrow (it was a wheel-tracked, non-fertilised furrow) on the other side of the row maintained or increased silage yield by up to $26 \%$ and increase $\mathrm{N}$ uptake in silage by up to $21 \%$.

Field experiments carried out on a bare soil by Abassi et al. (2003) were solely based on water and solute transport parameters; the solute (i.e. bromide) being dissolved in the irrigation water. The author's objective was to analyse the impact of water depth and water application depth on solute leaching. The conclusions relative to the impact of high water flow depths on WAD and the risks of solute leaching are very close to those presented in this paper.

Mailhol et al. (2001) analysed a fertiliser technique which involves spreading a portion of the fertiliser application before furrow ridging. This operation masses the fertiliser on the top part of the ridge as shown in Fig. 1. .

The field experiments were carried out in 1999 on the loamy soil of Lavalette (Montpellier) where the corn crop was irrigated using $130 \mathrm{~m}$ long furrows. The presence of nitrogen on the upper part of the ridge at the end of the irrigation season attested to the low risk of $\mathrm{N}$ leaching during this period. Low irrigation and fertiliser application rates, which were matched to plant requirements, account for this result. But, the rainy events of October showed that the risks of $\mathrm{N}$ leaching were simply postponed to autumn. This indicates that irrigation must be managed with care to maximize $\mathrm{N}$ use efficiency (NUE). 


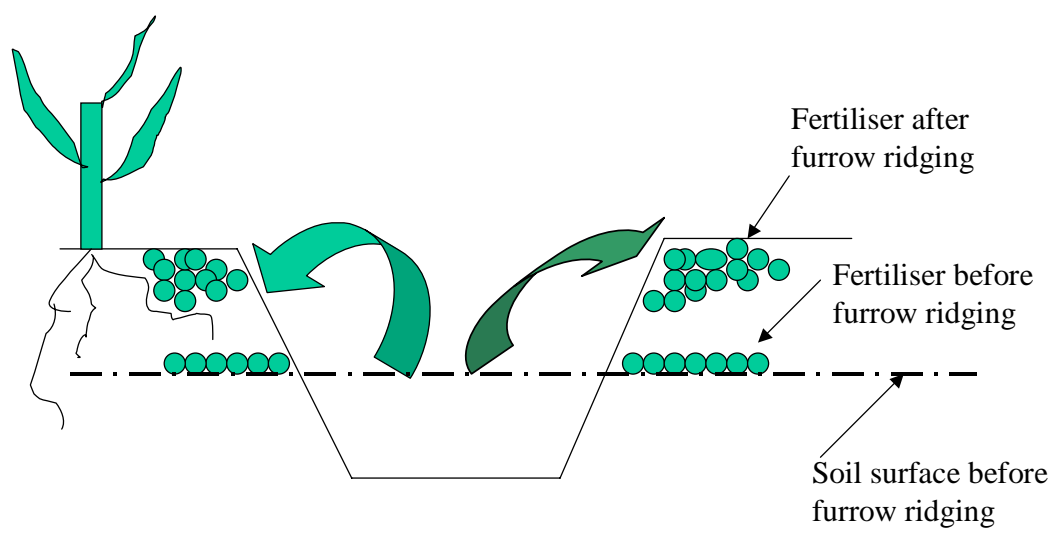

Fig. 1. Schematic representation of the fertiliser technique: fertiliser accumulation on the top of the ridge during the furrow ridging.

Due to a lack of data, the role of furrow water depth in NUE and N leaching was only briefly discussed at the end of the article. We also mentioned that corncobs appeared to be bigger over the last few meters of the blocked-end furrows than at other parts of the plot where the yield was measured $(12.7 \mathrm{Mg} / \mathrm{ha}$ with $\mathrm{Cv} \leq 5 \%)$. Over the last few furrow meters, water levels could reach the maximal furrow depth (i.e. $12-15 \mathrm{~cm}$ ), especially for furrows having short advance time (fast furrows), whereas on the other parts, the water depths rarely exceeded $5 \mathrm{~cm}$. Due to the heterogeneity of the advance process in furrow irrigation, variable situations may occur at the downstream end. For instance, moderate WAD may result from both water flow depth of $7 \mathrm{~cm}$ (for example) and short opportunity time in the case of furrows for which advance time is close to cut-off time.

The corn yield of $13.8 \mathrm{Mg} / \mathrm{ha}$ obtained with a full-irrigated sprinkler treatment, although not much higher than for the furrow irrigated plot, raises the issue of NUE dependence on fertilisation and irrigation practices. The fertiliser accumulated at the top part of the ridge during the ridging operation, can migrate to deeper soil layers if high water depth conditions exist in the furrow, or as the result of substantial rainfall events. The $\mathrm{N}$ residues located on the top of the ridge should, in theory be less affected by low flow depth conditions than by high flow depth conditions found at downstream parts of the furrow. This hypothesis has been tested in Mailhol (2001) with the water and solute transport numerical code HYDRUS2D (Simunek et al., 1999). $\mathrm{N}$ homogenisation within the root system (transfer of $\mathrm{N}$ from the top of the ridge to a vertical of the furrow bed) was shown. This result is consistent with the findings of Abassi et al., 2003 and Abassi et al., 2004.

With low water levels, capillary forces are mainly responsible for nitrogen displacement, which generally results in $\mathrm{N}$ increase on the upper part of the ridge. With high water levels, both capillary and gravity forces contribute to nitrogen displacement from the top to deeper soil layers. Assuming that the nitrogen movement is limited to the root zone, one can say that all the conditions required to obtain a good NUE are met. Nevertheless, if the water application depth is too high the risks of nitrogen leaching increase significantly, and 
consequently, NUE may decrease when the nitrogen application matches plant requirements.

Because the field experiments carried out on Lavalette in 1999 did not allow us to evaluate the impact of infiltration conditions both on $\mathrm{N}$ leaching and on NUE, infiltration tests were performed in 2002. They are described in this article, the objective being to validate the previous findings-interpretations and to estimate the risks of $\mathrm{N}$ leaching for high irrigation rates, linked to inlet discharge rates, opportunity times or ponding.

\section{Materials and methods}

\subsection{The experimental approach}

Infiltration tests on 1.5-m long blocked furrows were performed during the 2002 cropping season on the experimental plot of Lavalette at the Cemagref Institute in Montpellier $\left(42.5^{\circ} \mathrm{N}\right.$, $85^{\circ} \mathrm{W}$ ) on a soil composed of $49 \%$ silt, $30 \%$ sand and $21 \%$ clay having a maximal available water storage (MAWS) of $160 \mathrm{~mm} / \mathrm{m}$. The furrow infiltration treatment took place inside a corn plot irrigated using a travelling rain gun system (TRGS). This corn plot, sown on 04/25, also contained three treatments. A full-irrigated treatment (FIT), a zero $\mathrm{N}$ treatment (ONT), both irrigated using the TRGS and a dry treatment (DT), which received only one irrigation at sowing. Each of these three treatment sites had an area of 0.25 ha approximately and was equipped with mercury tensiometers located at depths of 30 and $180 \mathrm{~cm}$ and spaced at $30 \mathrm{~cm}$ along the vertical. Precautions were taken to prevent system impacts on the furrow treatment by maintaining a large non-irrigated area between them (Fig. 2a). The limited size of the furrow infiltration test allowed a better control of water application depths and reduced the impacts of large-scale heterogeneity on the interpretation of the results (Abassi et al., 2004). In addition, this protocol suits the objective of this work which focuses on nitrogen fate when a furrow is locally affected by high water flow depths. The corn (Samsara grain species) was sown on May 5, 2 days after the first fertiliser application (90 kg of N per ha). A second fertiliser application was made (100 kg of $\mathrm{N}$ per ha) just before furrow ridging (seven furrows only on a limited length of few meters) at the five-leaf stage. During the same period, an equivalent amount of fertiliser was applied to the rest of the plot irrigated with the rain gun system. Excepted ONT, all the irrigated treatments received the same N amount; they only 
differ among themselves by the irrigation conditions.

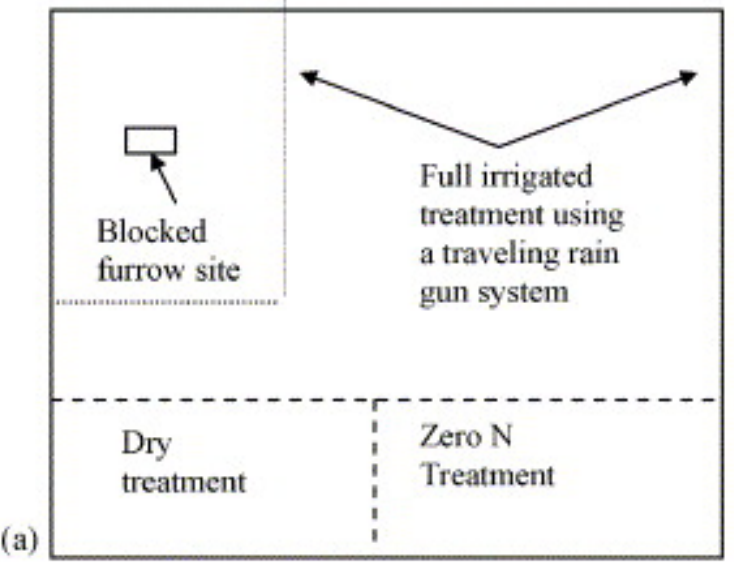

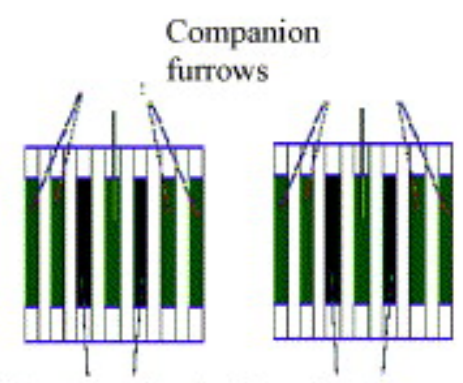

(b) Location 1 Location 2

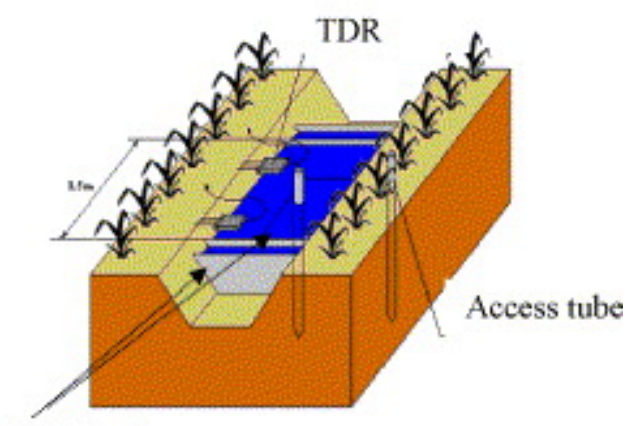

(c) Metallic plaques

Fig. 2.-Presentation of the-field experiments:-(a)-generat view, (b) the blocked furrow experiment and (c) the measurement apparatus used for location 1 and location 2.

The experimental apparatus is presented in Fig. 2c. In order to be as close as possible to real furrow irrigation conditions, a constant water depth was maintained within seven furrows. A constant water depth was also maintained at the upstream and downstream parts of the blocked furrows by adding a given water volume within the metallic plaques used to block the furrows. The furrow treatment experiment was carried out at two locations, with a different water depth maintained at each location: $h_{1}(12 \mathrm{~cm})$ for location 1 and $h_{2}(7 \mathrm{~cm})$ for location 2 (Fig. 2b) for the first irrigation event, then 10 and $5 \mathrm{~cm}$ for the subsequent irrigation events. An initial volume of water equivalent to the required water depth was delivered within the furrow, covered beforehand with a plastic film. The latter was pulled away at initial time $t=0$. The estimation of the initial volume was based on furrow cross-section measurements and was subsequently calculated using the furrow geometry parameters generated. These water depths were maintained by adding a measured amount of water when the water level reached the desired depth as measured on a metallic scale installed in the furrow bed. Water level was maintained within $\pm 0.5 \mathrm{~cm}$ of the desired depth. A cumulative infiltration curve was thus obtained for each event and furrow monitored.

A neutron access tube was inserted in the furrow bottom and a second at the ridge top, both allowing the soil water content to be measured to a depth of $190 \mathrm{~cm}$. Two $30-\mathrm{cm} \mathrm{CS6115}$ Campbell TDR probes were inserted into the soil on the top ridge (at 10-cm depth) to monitor the soil water content in the first soil layer. Bulk density was measured before the first and the second infiltration test using a surface Gamma densimeter.

Three irrigation treatments (corresponding to the infiltration tests) were performed during the cropping season; the dates and amount of water applied are presented in Table 1. Just before the first irrigation event ( 2 July), then 8 days later ( 11 July) and on the 25 September 
(before harvesting), soil samples for $\mathrm{N}$ analysis were collected using the auger under the ridge at the following depths: $0-6.5,6.5-13,13-36.5,36.5-66.5,66.5-96.5$ and $96.5-$ $126.5 \mathrm{~cm}$ and under the furrow bed at the following depths: 0-6.5, 6.5-23.5, 23.5-53.5, $53.5-83.5,83.5-113.5$ and $113.5-143.5 \mathrm{~cm}$. The two reference levels are separated by a furrow depth of $15 \mathrm{~cm}$. For each depth, four soil samples were mixed. Precautions were taken to ensure that the infiltration tests were not disturbed (careful refilling of the holes where soil was collected). Lastly, the crop status was observed during the cropping cycle at the location of the furrow infiltration tests. This observation refers to elements linked to leaf area index estimation (number of active leafs and leaf size and plant elevation) and cob dimensions. These elements reflecting the crop status were compared to those of FIT. FIT, for which water supply matches plant requirements (a water amount of $340 \mathrm{~mm}$ was delivered in 11 applications at a rate that prevented ponding), is assumed to provide yield potential. Fertiliser applications and the initial soil nitrogen profile (just before sowing) for FIT are similar to those of the furrow treatments. Soil samples were also collected for soil $\mathrm{N}$ profile determination for the three treatments: FIT, ONT and DT. A first collection of soil samples (at $0-10 \mathrm{~cm}$, then at each $30 \mathrm{~cm}$ depth until $150 \mathrm{~cm}$ ) was made just before sowing and a second at the end of September, a few days before harvesting. For yield estimation, seven sub-plots were harvested on FIT. The yield estimation on the furrow treatment was based on the harvesting of two crop lines belonging to each location along a $2 \mathrm{~m}$ strip. The representative sample of each location contained approximately 16 plants (cut at the soil level) in an area of $1.6 \mathrm{~m}^{2}$.

Table 1. Water application depths (WAD, in $\mathrm{mm}$ ) and soil water content variation (SWRV, in $\mathrm{mm})$

\begin{tabular}{|l|l|l|l|l|l|}
\hline Irrigation & Julian date & \multicolumn{2}{|c|}{ Site 1 } & \multicolumn{2}{c|}{ Site 2 } \\
\hline & & SWRV & WAD & SWRV & WAD \\
\hline 1 & 184 & 119 & 240 & 87 & 175 \\
\hline 2 & 198 & 103 & 104 & 67 & 60 \\
\hline 3 & 214 & 52 & 80 & 53 & 57 \\
\hline
\end{tabular}

\subsection{The modelling approach using the 2D water and solute transport model HYDRUS- 2D}

Due to the importance of 2D water and the solute transfer process with regards to the fertilisation technique, a nitrogen balance under furrow irrigation is not easy to obtain when the irrigation conditions result in a significant difference in the soil $\mathrm{N}$ profile between the ridge and the furrow bed. A modelling approach, taking into account these circumstances, is required to analyse risks of $\mathrm{N}$ leaching resulting from irrigation and fertilisation practices.

Modelling is used to simulate the water and nitrogen transport process occurring during the irrigation period. Due to domain geometry and the specificity of the fertilisation practice, the 2D water and solute transport model HYDRUS-2D (Simunek et al., 1999) is used. This modelling approach of the 2D transfer process was calibrated and validated for the soil context of Lavalette in Mailhol et al. (2001). The van Genuchten retention curve parameters (van Genuchten, 1980): $\alpha, n, m, \theta_{\mathrm{s}}$ and $\theta_{\mathrm{r}}$ and saturated conductivity $K_{\mathrm{s}}$, govern the water transfer process and molecular diffusion, $D_{\mathrm{m}}$, transverse, $D_{\mathrm{T}}$, and longitudinal dispersivity, $D_{\mathrm{L}}$, and the adsorption isotherm constant, $K_{\mathrm{d}}$, govern the solute transfer process. The sink term, 
$S$, in the transfer equations, represents the volume of water removed per unit time from a unit volume of soil due to plant water uptake.

\subsection{Initial and boundary conditions}

Initial and boundary conditions for the simulation of an irrigation event are presented in Fig. 3 . Note that initial $\theta(x, z)$ conditions to simulate the redistribution process, are those calculated by the model at the end of the irrigation event that precedes redistribution; $h_{i}(i=1$ for location 1 and $i=2$ for location 2 ) is set to 0 so the evapotranspiration flux condition affects both the furrow bed and the ridge.

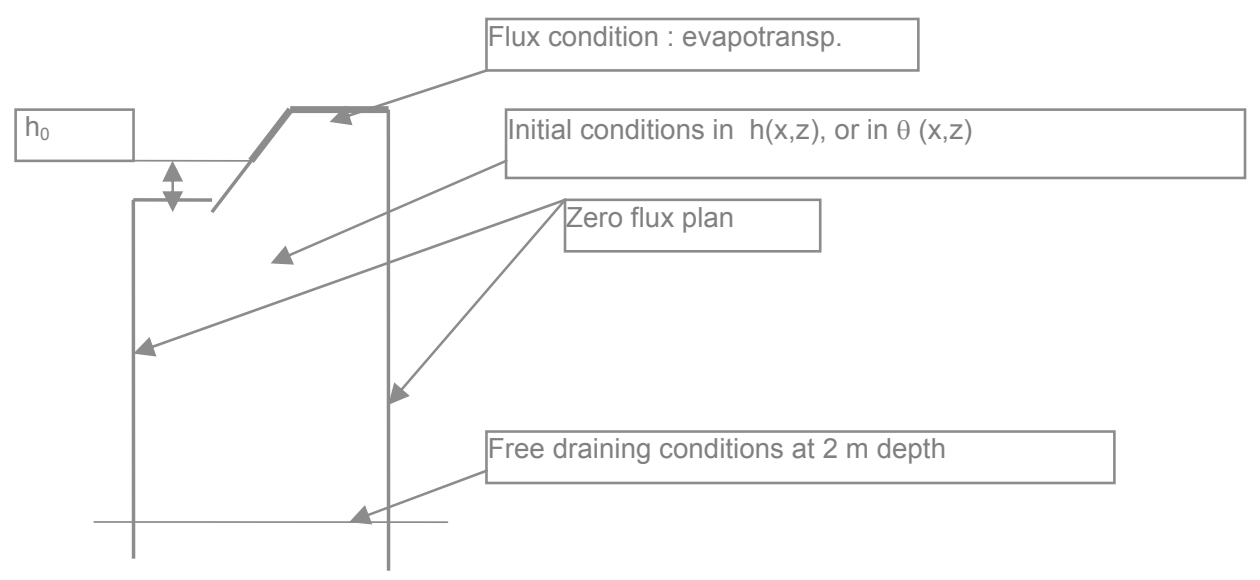

Fig. 3. Schematic representation of the initial and boundary conditions for an irrigation event.

The initial concentration within the flow region required by the solute transfer equation is:

$$
c\left(x, z, t_{0}\right)=c(x, z)
$$

A $c(x, z)$ value is set at each top of the triangular elements constituting the network within which the flow region is divided. Before the first irrigation event, this $c$ value is obtained from the measured $\mathrm{N}$ soil profile, where interpolations are made between the ridge profile and furrow bed profile. Initial nitrogen conditions required to simulate redistribution, are obtained from the last time step of the previous simulated irrigation event. The third type (Cauchy type) of boundary conditions are used with a value $c_{0}=0$ of the water concentration entering the flow region.

\section{Results and discussion}

\subsection{Cumulative infiltration}

The impact of water flow depth on the cumulative infiltration $(\mathrm{Cl})$ is more significant after the first irrigation event, although changes in the shape of the cross-section mitigates the affect of water depth on $\mathrm{Cl}$. For short times, the cumulative infiltration curves for the two depths of water, $h_{1}$ and $h_{2}$, were similar during first irrigation unlike those that follow. This is probably due to soil conditions (dry soil unstructured). For an opportunity time of $3 \mathrm{~h}$, the difference in 
cumulative infiltration only reaches $30 \mathrm{~mm}$ (around $15 \%: 210 \mathrm{~mm}$ for $h_{1}=12 \mathrm{~cm}$ versus $180 \mathrm{~mm}$ for $h_{2}=7 \mathrm{~cm}$ ). These results are presented in Table 1 . The water depth impact on cumulative infiltration is a little bit higher $(20 \%)$ following the first irrigation. But the impact of water depth on infiltration rate is significant as shown in Abassi et al. (2003). The shallow bulk density values are much lower before the first irrigation test $\left(1.3 \mathrm{~g} / \mathrm{cm}^{3}\right)$ than before the second $\left(1.5 \mathrm{~g} / \mathrm{cm}^{3}\right)$ as the compaction effect brought about by the subsequent water applications allows the soil to regain its structure lost during tillage operation or furrow ridging (Or, 1996 and Mailhol et al., 1999).

The results of infiltration tests are presented in Table 1. To comply with standard furrow irrigation practices, the greatest amount of water was delivered during the first irrigation event. The WAD of $240 \mathrm{~mm}$ on location 1 results from a water depth of $12 \mathrm{~cm}$ over $5 \mathrm{~h}$ and that of $175 \mathrm{~mm}$ on location 2 results in a water depth of $7 \mathrm{~cm}$ over $3.5 \mathrm{~h}$. Opportunity times, which comprise both the required time for water supply and recession time, differ due to the different flow depths. The WAD difference is due both to the water depths and opportunity time. Although not detailed here, as it is beyond the scope of this article, it should be noted that the wetted perimeter impact on cumulative infiltration concurs with the results of Oyonarte et al. (2002).

In the farm context, WAD can often exceed $150 \mathrm{~mm}$ for the first irrigation event as plots are often longer than 200 m (Gonzalez, 1991, Mailhol and Gonzalez, 1993, Mailhol et al., 1999 and Zairi et al., 1998). With these very high WAD values, which result from long advance times, the risks of deep percolation and $\mathrm{N}$ fertiliser leaching are considerably greater than for the other irrigation events. Although high, the $240 \mathrm{~mm}$ WAD on location 1 is not unrealistic for a first irrigation event. However, it should be noted that our objective is also to test the fertilisation technique in relation to environmental risk and yield loss, the latter resulting from leaching at the cropping stage where the nitrogen requirements are highest.

The total WAD delivered to location 1 and location 2 is 424 and $292 \mathrm{~mm}$, respectively, while that delivered to the full sprinkler irrigated treatment is $346 \mathrm{~mm}$. Rainfall during the cropping cycle amounted to $310 \mathrm{~mm}$, and was most intense at the beginning and at the end of the cropping cycle.

The great differences in soil water content variation (SWRV) before irrigation and 24-h after and WAD (Table 1), for the first irrigation, probably result from drainage over the depth explored by the neutron probe system.

The soil water-content profiles under ridge and under furrow bed are not very different over a $20-\mathrm{cm}$ soil depth $48 \mathrm{~h}$ after irrigation, whatever the water amount delivered (Fig. $4 \mathrm{a}$ and b). Soil water content profiles performed 5 and 10 days after irrigation give the same result. Root water uptake helps to homogenise the soil water content at a given depth. It can, therefore, be stated that, from the soil surface to a depth subject to root influence (i.e. $1.4 \mathrm{~m}$ for corn), a water balance estimation based on a one-directional (1D) water transfer process may be carried out. This means that crop models based on 1D water transfer process could be used for water balance and crop yield predictions for furrow irrigated systems when $\mathrm{N}$ is assumed not to limit crop production. 
Soil Water Cont. $(\mathrm{cm} 3 / \mathrm{cm} 3)$
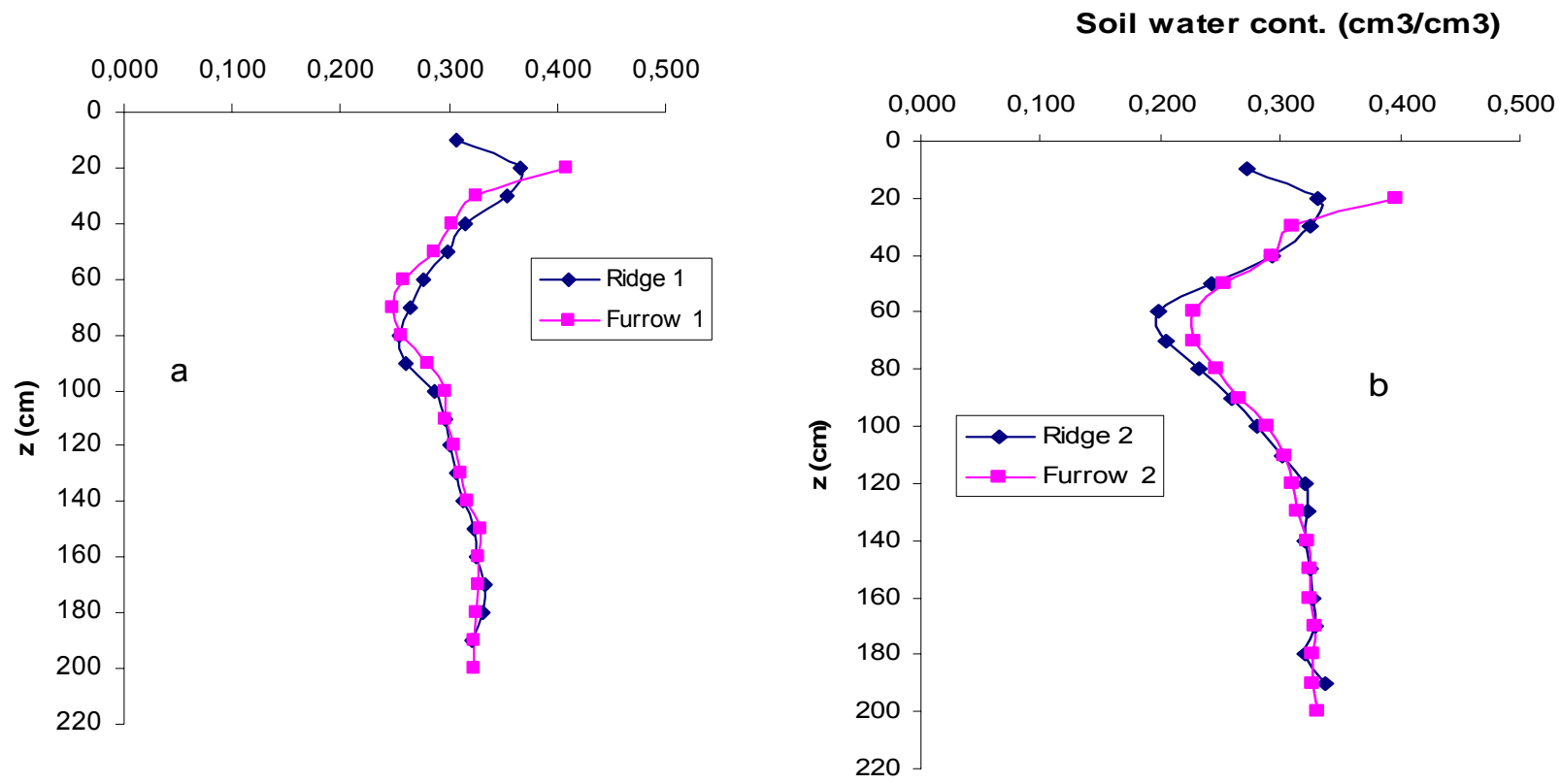

Fig. 4. Soil water content profile $48 \mathrm{~h}$ after first irrigation at location 1 (a) and after second irrigation at location 2 (b).

\subsection{Nitrogen balance}

The nitrogen profile $(0-150 \mathrm{~cm})$ obtained on 25 September yields a nitrogen amount of $55 \mathrm{~kg} / \mathrm{ha}$ under the furrow bed and $72 \mathrm{~kg} / \mathrm{ha}$ under the ridge for location 2, whereas no difference exists between the nitrogen amount under ridge and furrow bed on location 1 : $52 \mathrm{~kg} / \mathrm{ha}$ for both. The nitrogen measured on the plant components was 242, 122 and $88 \mathrm{~kg} / \mathrm{ha}$ for FIT, for DT and ONT, respectively. No N leaching occurred on DT according to tensiometer readings from 120 to $150 \mathrm{~cm}$ depth. Consequently, a mineralisation level of $104 \mathrm{~kg} / \mathrm{ha}$ is calculated from the nitrogen balance on 148 days resulting in a mineralisation rate of $0.7 \mathrm{~kg} / \mathrm{ha} / \mathrm{day}$. This value is similar to that obtained by_Nemeth (2001) on a dry treatment when a mineralisation rate of $0.85 \mathrm{~kg} / \mathrm{ha} / \mathrm{day}$ was obtained for a full-irrigated treatment by the same author. This value is in agreement with that found by Recous et al. (1994) in a similar environmental context to that of Lavalette and for a full-irrigated treatment. Tensiometer readings let us to presume substantial risks of $\mathrm{N}$ leaching on FIT. As no apparatus was installed to monitor $\mathrm{N}$ leaching, a mineralisation rate of $0.85 \mathrm{~kg} / \mathrm{ha} / \mathrm{day}$ for a period of 148 days is adopted to estimate $\mathrm{N}$ mineralisation for the FIT treatment: $133 \mathrm{~kg} / \mathrm{ha}$. Due to most favourable soil moisture conditions, mineralisation for FIT is generally significantly higher than for DT. A comparable value adopted for ONT would result in a higher leaching value than on FIT. This could be justified by the fact that as corn is less developed on ONT than on FIT, soil water reserve is less depleted than on FIT when the rainfall events of September occurred.

With a $\mathrm{N}$ initial profile of $63 \mathrm{~kg} / \mathrm{ha}$ (+ a N application of $190 \mathrm{~kg} / \mathrm{ha}$ ) and a $\mathrm{N}$ final profile of $77 \mathrm{~kg} / \mathrm{ha}$, the N leaching value calculated for FIT is $67 \mathrm{~kg} / \mathrm{ha}$. Owing to moderate WAD rates (lower than $35 \mathrm{~mm} / \mathrm{day}$ ) and a high soil water storage capacity (MAWS $=160 \mathrm{~mm} / \mathrm{m}$ ), there is no drainage on FIT until the end of August as confirmed by the tensiometer readings. As a 
result, one can state that $\mathrm{N}$ leaching on FIT is due to the rainfall events occurring at the end of the cropping cycle: $85 \mathrm{~mm}$ of rainfall occurred on 08/25, and $70 \mathrm{~mm}$ occurred on 09/16. $\mathrm{N}$ leaching can also have resulted from these rainfall events as the furrows remained blocked.

As location 1 is in the same environment conditions as FIT, their mineralisation and N plant uptake rates are considered equivalent (their indicators of plant status being very similar along the cropping cycle). Consequently, because the nitrogen profile for location 1 is homogeneous at the end of cropping cycle, the amount of $\mathrm{N}$ leaching calculated for this location is $92 \mathrm{~kg} / \mathrm{ha}$. The lower WAD on location 2 may explain why its $\mathrm{N}$ profile is less homogeneous than that of location 1 . But one can presume that $\mathrm{N}$ leaching at location 2 is somewhere between that of location 1 and FIT. Note that no denitrification and no gas losses are assumed in this nitrogen balance.

In spite of high WADs, especially for the first irrigation event, $\mathrm{N}$ leaching resulting solely from irrigation is not as high as expected for the furrow system. Indeed, although non-negligible, a $\mathrm{N}$ leaching value of $25 \mathrm{~kg} / \mathrm{ha}$ is estimated when the values of $67 \mathrm{~kg} / \mathrm{ha}$ derived from the FIT treatment is assumed to be the result of rainfall at the end of the cropping season on a soil near field capacity. The method which consists of estimating a $\mathrm{N}$ leaching value resulting from irrigation only is open to criticism. Indeed, from a theoretical point of view, it is difficult to distinguish the fraction of $\mathrm{N}$ leaching resulting from irrigation or from rainfall. The assumption, on which this estimation is based, is questionable even when the water and solute transfer conditions, on the FIT and the furrow locations, are very similar.

\subsection{Nitrogen distribution}

Water depth impact on $\mathrm{N}$ removal is shown in Fig. 5a and b where nitrogen profiles both under ridge and furrow bed, before and after first irrigation, are presented. At location 1, the nitrogen transfer is much higher under ridge than at location 2, highlighting the water depth impact on the $\mathrm{N}$ migration. It should be noted that differences in the concentration profile, between ridge and furrow, are not as marked at location 1 as at location 2 . This may be explained by a better $\mathrm{N}$ redistribution from the ridge to the furrow due to higher water depths. The $\mathrm{N}$ redistribution impact, illustrated in Fig. $5 \mathrm{a}$, shows higher $\mathrm{N}$ concentration levels at location 1 than at location 2 over a depth of $23 \mathrm{~cm}$. The difference in $\mathrm{N}$ transfer between the two locations is particularly high in the 15-65 cm depth interval. In 1999 (under low WAD and water depth level), the $\mathrm{N}$ concentration peak under ridge was attained at a much shallower depth (at $15 \mathrm{~cm}$ at the end of cropping cycle) than that obtained at location 2 in 2002 . Thus, we could presume that the highest $\mathrm{N}$ concentration could still be reasonably located on the upper part of the ridge at a period where the $\mathrm{N}$ plant requirements are the highest. Consequently, such a $\mathrm{N}$ soil profile at the development stage, when nitrogen requirements are high, should result in a better NUE for 2002 conditions than for those of 1999. 

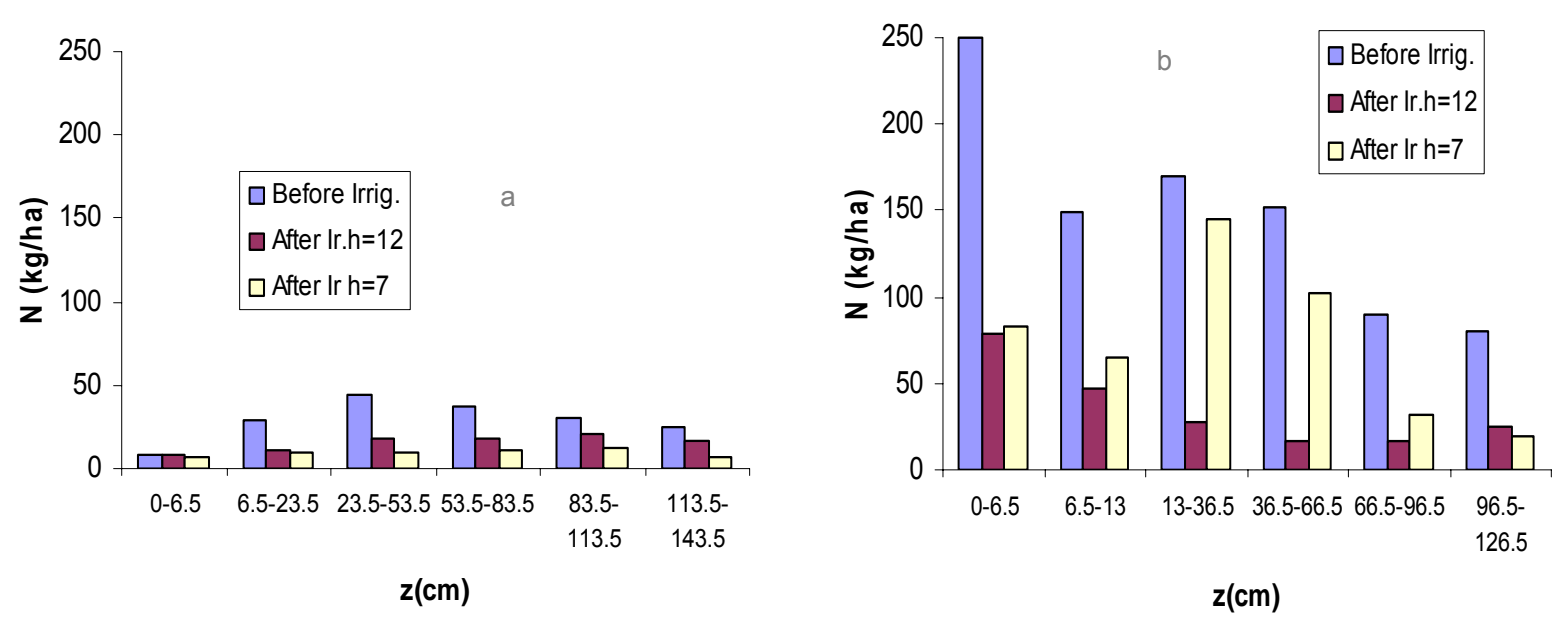

Fig.5 Nitrogen profile under the furrow bed (a) and under the ridge (b) before and few days after $1^{\text {st }}$ irrigation on location $1(h=12 \mathrm{~cm})$ and location $2(h=7 \mathrm{~cm})$

Fig. 5. Nitrogen profile under the furrow bed (a) and under the ridge (b) before and few days after first irrigation at location $1(h=12 \mathrm{~cm})$ and location $2(h=7 \mathrm{~cm})$.

\subsection{Impact on the crop yield}

One of the objectives of our work was to identify WAD levels that could lead to yield loss (due to $\mathrm{N}$ stress) resulting from $\mathrm{N}$ leaching in the context of the analysed fertilisation practice. It was for this reason that a high water application depth (WAD $=240 \mathrm{~mm}$ ), more than two times greater than that delivered during the first irrigation of 1999, was applied on location 1. As evoked earlier, such a WAD is often delivered to longer plots $(L>250 \mathrm{~m})$ during the initial irrigation. It is to be assumed that such a high WAD provokes $\mathrm{N}$ leaching and $\mathrm{N}$ stress to plants when a 1D transfer process such as that prevailing for the sprinkler treatment is assumed.

Yield estimations for a $1.6 \mathrm{~m}^{2}$ area does not allow reliable conclusions to be made on possible corn yield variations resulting from a water depth difference (or WAD difference).

That is the reason why comparisons were made at a given development stage between plant status indicators measured on the two locations and those measured on FIT. These indicators are the leaf area index (LAI) during flowering and cobs size and weight at maturity. On the basis of these comparisons, a value of $14.2 \mathrm{Mg} / \mathrm{ha}$ is proposed as a yield estimation for location 1 and $13.6 \mathrm{Mg} / \mathrm{ha}$ for location 2.

These yield values are very close to the potential yield value of the corn variety (i.e. 14.5 Mg/ha), although not fully reached with the FIT (13.8 Mg/ha, Cv $=4 \%)$. Hence it can be stated that crop development was not affected by $\mathrm{N}$ stress resulting from eventual $\mathrm{N}$ leaching or a nitrogen use efficiency problem. One can even guess that the higher yield gains obtained in 2002 (under high flow depths or WAD conditions) in comparison with those of 1999 (12.7 Mg/ha), results from a better NUE.

\subsection{Hydrus-2D application}




\subsubsection{The water transfer parameters}

The soil parameters, $\theta_{\mathrm{s}}$ (saturation water content), $\theta_{\mathrm{r}}$ (residual water content) and the shape parameters $\alpha, n$ and $m$ ( $m=1-1 / n$ according to the Mualem model) of the van Genuchten equation (van Genuchten, 1980, used in Mailhol et al., 2001) did not result in a satisfactory simulation of the cumulative infiltration. As discussed above, the hydraulic parameters of the soil change from the first to subsequent irrigation events. A new calibration was made using the parameters sets (i.e. $\theta_{\mathrm{s}}=0.37$ and $\theta_{\mathrm{r}}=0.05$ ), obtained from an infiltration test (using the double ring method) performed on the plot near our experiment (Mailhol, 2003). Two layers were considered in order to take into account the tillage effect which results in a lower bulk density from the surface to a $20 \mathrm{~cm}$ depth. Manual calibration is preferred to the automatic inverse method proposed by HYDRUS because the two objective functions: cumulative infiltration and $\theta(z)$ profile were not monitored at the same time. The soil water content profile was established $48 \mathrm{~h}$ after irrigation. The shape parameters are $\alpha=0.1 \mathrm{~cm}^{-1}, n=1.87$ for first layer $(0-20 \mathrm{~cm})$ and $\alpha=0.007, n=1.65$ for second layer $(20-150 \mathrm{~cm})$ associated to saturated conductivity $\left(K_{\mathrm{s}}\right)$ values of $4 \mathrm{~cm} / \mathrm{h}$ (first layer) and $2 \mathrm{~cm} / \mathrm{h}$ (second layer) give acceptable results for both cumulative infiltration and soil water redistribution of the first irrigation. Acceptable concordance between measured and simulated cumulative infiltration for the third irrigation event is obtained (Fig. $6 a$ and b) when saturated conductivity is reduced from 4.0 to $1.7 \mathrm{~cm} / \mathrm{h}$ for the first layer and from 2.0 to $1.6 \mathrm{~cm} / \mathrm{h}$ for the second layer, the latter is close to the value proposed in Mailhol et al. (2001). Due to shallow cracks, some discrepancies are nevertheless noticeable at short times. Modification of soil hydraulic properties from the first to subsequent irrigation events, along with the presence of cracks, highlights the limitations of the mechanistic approach.
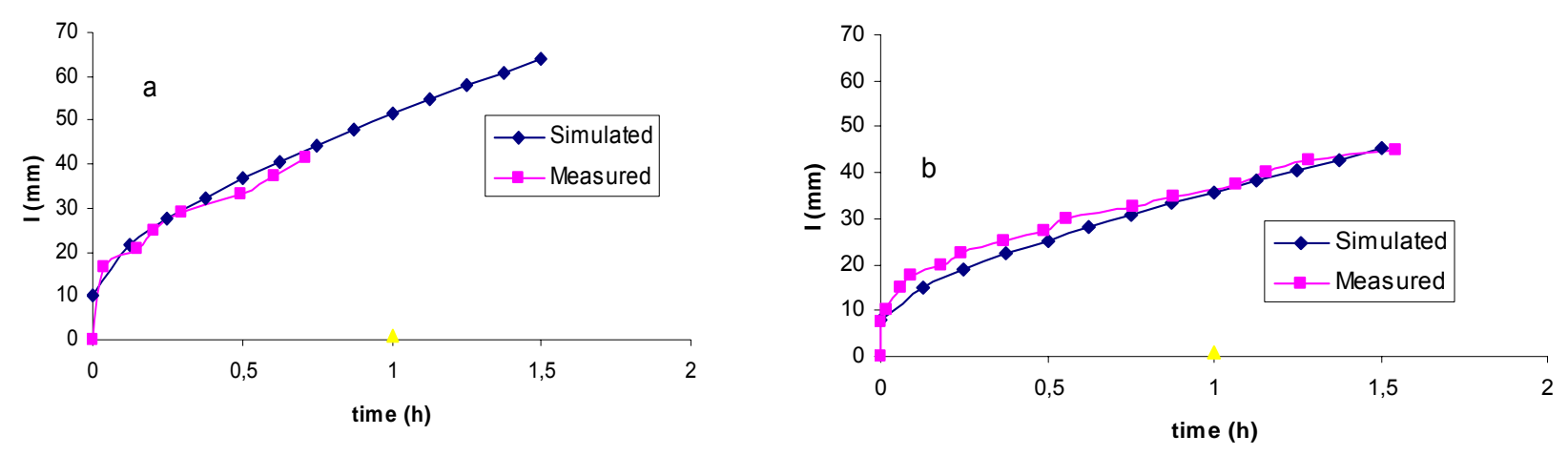

Fig. 6. Simulated vs Measured cumulative infiltration for $3^{\text {rd }}$ irrigation on location 1 (a) and location 2 (b)

\subsubsection{The solute transfer parameters}

The solute transport equation has to be solved for each solute present in the soil. There are three solutes are present in the soil before first irrigation: $\mathrm{NH}_{4}{ }^{+}, \mathrm{NO}_{2}{ }^{-}$and $\mathrm{NO}_{3}{ }^{-}$as ammonium nitrate was the fertiliser used in these experiments. These three solutes have different characteristics and can inter-react. Adsorption is only considered for $\mathrm{NH}_{4}{ }^{+}$; as its isotherm partition coefficient, $K_{d}(\mathrm{~L} / \mathrm{kg})$, which linearly relates the solute in the soil solution and in the sorption locations, is in the range of 0.3-3 L/kg (Vereecken et al., 1991). These are suitable values for the soil type of Lavalette, whereas those of $\mathrm{NO}_{2}^{-}$and $\mathrm{NO}_{3}^{-}$are very low $\left(10^{-6} \mathrm{~L} / \mathrm{kg}\right)$ because they are not absorbed by the porous matrix. We also consider degradation from 
$\mathrm{NH}_{4}{ }^{+}$to $\mathrm{NO}_{2}{ }^{-}$and from $\mathrm{NO}_{2}{ }^{-}$to $\mathrm{NO}_{3}{ }^{-}$, with a first order rate constant $\mu_{\mathrm{NH} 4-\mathrm{NO} 2}$ and $\mu_{\mathrm{NO} 2-\mathrm{NO} 3}$, respectively. No other reaction or degradation is considered. A sink term is added corresponding to the solute consumed by the plants. The three coupled equations to be solved become the following:

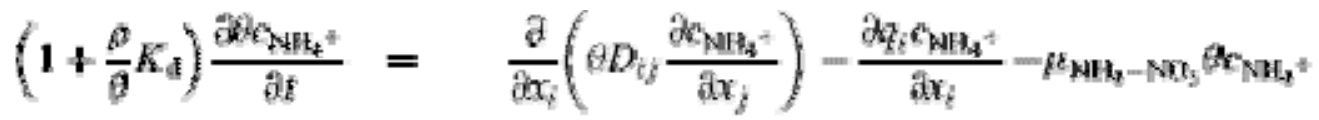

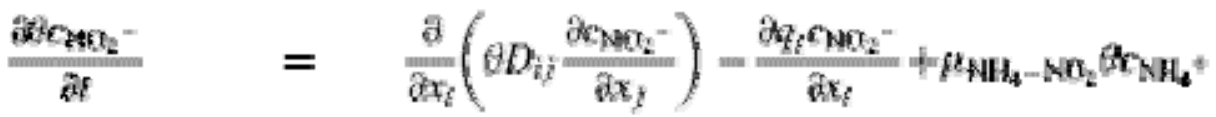

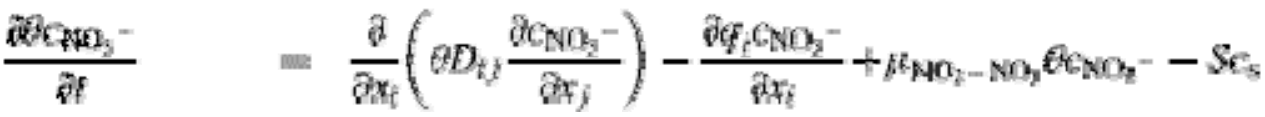

A week after the first irrigation event, the soil samples showed that only $\mathrm{NO}_{3}{ }^{-}$is present in the soil. Except for bulk density in the upper part of the ridge, the solute transport parameters, in first try, were assumed to be constant according to soil depth. The molecular diffusion $D_{\mathrm{m}}$ was set at $1.55 \mathrm{~cm}^{2} / \mathrm{h}$ (as proposed by Beven et al., 1993), and the $D_{\mathrm{L}}$ and $D_{\mathrm{\top}}$ values are those obtained in Mailhol et al. (2001), i.e. 15 and $2 \mathrm{~cm}$, respectively. They are assumed to be independent of the initial soil water content, as considered by Flury et al. (1994). Generally, the longitudinal dispersivity can be considered equal to one-tenth of the profile depth and $D_{\mathrm{T}}=D_{\mathrm{L}} / 10$, as proposed by some authors (Beven et al., 1993 and Cote et al., 2001). But these parameters are not sensitive under the actual flow conditions of the simulated period and, substantial modifications (a 10-fold increase or decrease) did not resulted in simulation improvements. The values of first order degradation rate constants were set to $0.05 \mathrm{~h}^{-1}$ for $\mu_{\mathrm{NH} 4-\mathrm{NO} 2}$ and $0.1 \mathrm{~h}^{-1}$ for $\mu_{\mathrm{NO} 2-\mathrm{NO} 3}$ as proposed in Mishra and Misra (1993). Using these values and the minimal value for the isotherm partition coefficient $K_{d}$ $(0.3 \mathrm{~L} / \mathrm{kg})$ and the previous values of first order degradation rate constants, the simulations were not very satisfactory, especially for the deeper layers. In order to obtain better results, two parameter sets for $K_{d}$ for the first order degradation constants were calibrated for two soil layers. The $K_{d}$ parameter set has the following values: 0.1 and $0.02 \mathrm{~L} / \mathrm{kg}$ for the first and second layer, respectively. Regarding the first order degradation constant, it was not necessary to consider two different values for $\mu_{\mathrm{NH} 4-\mathrm{NO} 2}$ and $\mu_{\mathrm{NO} 2-\mathrm{NO} 3}$. This common value is 0.02 and $0.005 \mathrm{~h}^{-1}$ for the first and second layer, respectively. In spite of these calibration efforts, the lowest values are still over estimated compared with the highest that are correctly simulated. The results presented in Fig. 7 are given using a 1D curve in order to provide a better visual comparison. Note that a third nitrogen profile between ridge and furrow would have been useful to improve our understanding of the nitrogen redistribution process and for better model simulation. But the infiltration conditions within our blocked furrow set would have probably been significantly affected by obtaining the needed soil samples to obtain another $\mathrm{N}$ soil profile. 

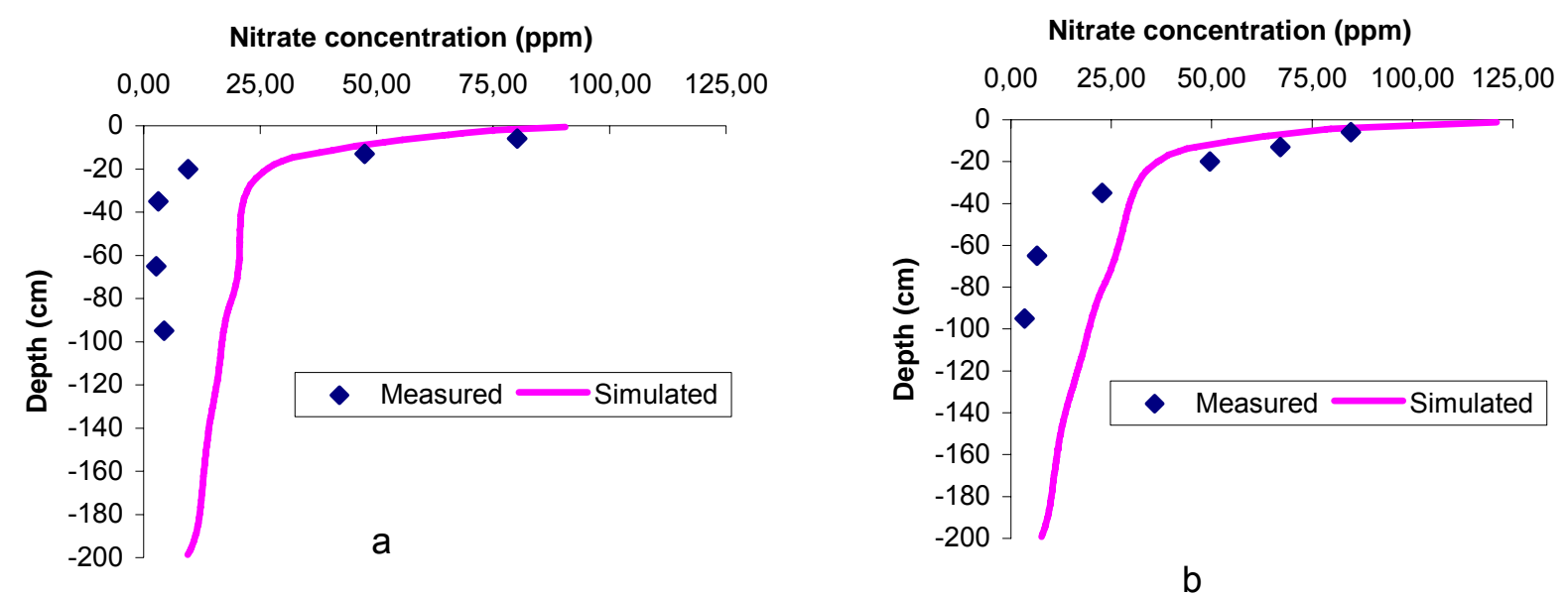

Fig. 7. Simulated vs. measured nitrogen profile under the ridged after first irrigation on location 1 (a) and after first irrigation at location 2 (b).

The model simulation confirms experimental results: solute profile homogenisation is better under high WAD and solute concentrations remain high in the first layers of location 2 . The latter represents an environmental risk in the case of heavy rains after the cropping season.

\subsubsection{Simulation of solute transport along the cropping cycle}

The sink terms of the transfer equations cannot be neglected when the simulation is carried out along the cropping cycle in contrast with irrigation events. The Feddes approach (Feddes et al., 1978), where a root density value is assigned to the specific nodes, allows plant water uptake to be simulated. The sink term of the solute transport equation (not simulated by HYDRUS), corresponding to the plant water uptake, is set using a $\mathrm{N}$ concentration in the transpired water (calculated on the basis of plant $\mathrm{N}$ requirements at specific stages). This corresponds to mineralisation and is set at a constant value of $0.85 \mathrm{~kg} / \mathrm{ha} /$ day derived from the TRGS treatments.

The evolution of the nitrogen concentration at $z=1.4 \mathrm{~m}$ (maximal root depth being $1.2 \mathrm{~m}$ for corn at Lavalette) along the cropping cycle is presented in Fig. 8 . The simulation results show that nitrogen concentration has significantly increased under furrow beds and decreased under ridge. This results in a homogenised $\mathrm{N}$ soil profile just after the first irrigation event, especially for high WAD (location 1). Simulation results concur with the measured nitrogen profile at the end of the cropping cycle. The small changes in $\mathrm{N}$ concentrations just under the root zone and along the cropping cycle, attest of the moderate risks of $\mathrm{N}$ leaching even under high WAD. 


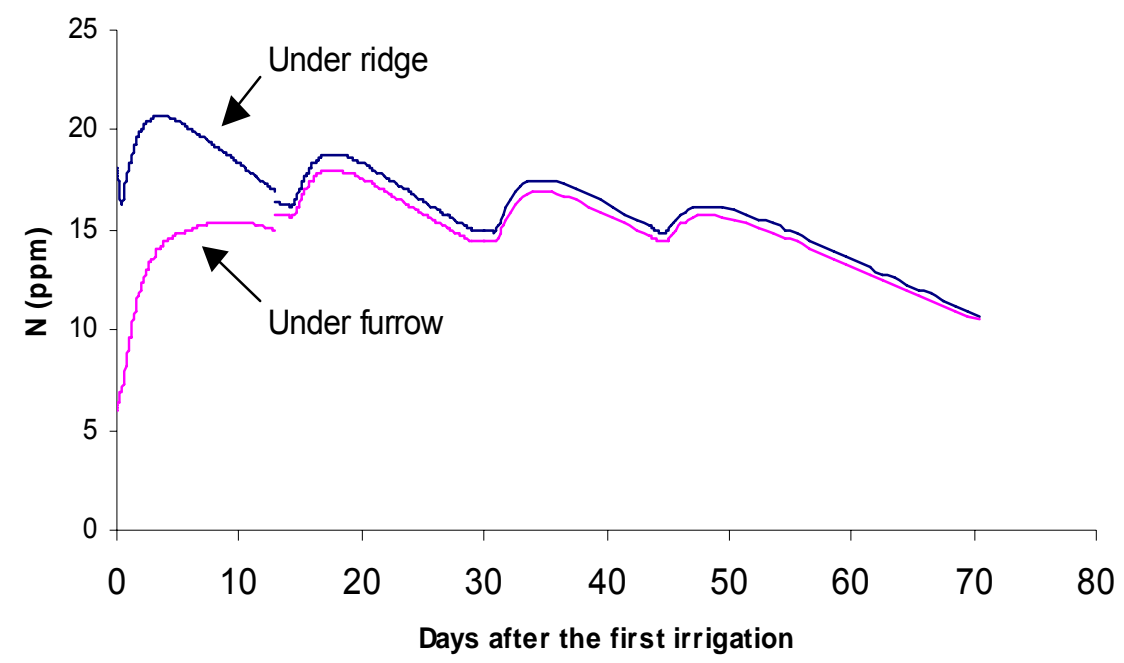

Fig. 8. Simulation of the nitrogen concentration from 07/01 to 09/10 just under the root zone at the vertical of the furrow and the ridge.

The amount of $\mathrm{N}$ leaching over a $1.4 \mathrm{~m}$ depth is 22 and $10 \mathrm{~kg} / \mathrm{ha}$ for location 1 and location 2 , respectively, just before the $08 / 25$ rainfall event. The $\mathrm{N}$ leaching value of $22 \mathrm{~kg} / \mathrm{ha}$ is close to the $\mathrm{N}$ leaching value (i.e. $25 \mathrm{~kg} / \mathrm{ha}$ ) deduced from the nitrogen balance estimation based on measured $\mathrm{N}$ soil profiles. The values obtained (approximately $11 \%$ of the nitrogen application) in the context of Lavalette for high infiltration rates seem realistic compared to those obtained by Popova et al. (2000) with $2 \mathrm{~m}$ depth lysimeters (7-8\% of nitrogen application). The $22 \mathrm{~kg}$ of $\mathrm{N}$ leaching cannot be considered negligible. But we have to keep in mind that this probable value results from extreme flow conditions. Although the fertilisation technique, which involves depositing the fertiliser in the irrigated furrow, can generate more leaching risks than the one tested at Lavalette, the much higher WAD of Lavalette would result in a significantly higher $\mathrm{N}$ leaching value on a soil with similar hydraulic properties. But one must recognize that the comparison with the Popova results is more sustainable (the values being so much close) when the simulation is performed over a $2 \mathrm{~m}$ depth instead of $1.4 \mathrm{~m}$.

\section{Conclusion}

\subsection{About the 2002 study}

The impact of water flow depths (in the furrow bed) and water application depth (WAD) on nitrate displacement from the upper part of the ridge to the deeper soil layers is shown in this work and is based on field measurements and modelling. Under high flow depths and WAD, this nitrogen removal results in a homogeneous $\mathrm{N}$ profile within the root reservoir that should contribute to an increase in nitrogen use efficiency. In spite of a substantial WAD, the amount of $\mathrm{N}$ leaching is not considerably high: $22 \mathrm{~kg} \mathrm{~N} / \mathrm{ha}$ under the soil conditions of Lavalette (a deep soil with a high MAWS value). This value, which represents $11 \%$ of nitrogen application, was obtained through field measurements and simulations using a modelling approach suited to 2D water and solute transfer: HYDRUS-2D. The measured soil nitrogen profile both under ridge and under furrow confirms previous research work which underlines the utility of a $2 \mathrm{D}$ water and solute transfer modelling rather than a 1D approach to simulate 
the nitrogen distribution and to estimate leaching risks according to the fertilisation technique analysed in this study.

The changes in soil conditions over subsequent irrigations (mainly from first to second watering) affect the predictive character of the mechanistic model. Indeed, it is highly recommended to calibrate the model parameters for each irrigation events (especially for the first and second irrigation simulations). The knowledge of the temporal variability process of the soil hydraulic parameters would improve model predictions. This concurs with the conclusions of Abassi et al. (2004).

In spite of first irrigation levels of $240 \mathrm{~mm}$ and nitrogen applications calibrated with plant requirements, no $\mathrm{N}$ stress occurred as attested by the grain yield level obtained. As suggested in previous works, the fertilisation technique mitigates the risks of nitrogen leaching over the irrigation season. But, as under sprinkler irrigation conditions, these risks are simply postponed to the winter period if inadequate WADs are delivered. Moreover, low WADs may provoke water stress conditions which can impact on nitrogen use efficiency.

\subsection{About the 1999 study}

There was a marked difference in the average yield value $(12.7 \mathrm{Mg} / \mathrm{ha})$ obtained on the furrow irrigated plot in 1999 at Lavalette and that obtained $(13.8 \mathrm{Mg} / \mathrm{ha})$ for the same year on the full-irrigated sprinkler treatment. It was of course stated that this difference did not result from water stress. The fact that there is no yield difference between the two analysed systems in 2002 is noteworthy, and leads us believe that nitrogen use efficiency under the conditions of 1999 (low flow depths and WAD in the area of the measured locations) is probably lower than under the experimental conditions of 2002. The presence of nitrogen, on the upper part of the ridge at the end of the 1999 cropping cycle, and thereby not consumed by the plants, strengthens this assumption, as the amount of $\mathrm{N}$ applied (i.e. $180 \mathrm{~kg} / \mathrm{ha}$ ) in 1999 was adjusted to plant requirements and local conditions.

The results established for the 2 years further highlight the necessity of good management practices for both irrigation and fertilisation to increase $\mathrm{N}$ plant uptake and to reduce $\mathrm{N}$ leaching over the irrigation and the inter-cropping season.

\section{References}

F. Abassi, D. Adamsen, J. Hunsaker, J. Feyen, P. Shouse and M.Th. van Genuchten, Effects of flow depth on water flow and solute transport in furrow irrigation. Field data analysis, $J$. Irrig. Drain. Eng. 129 (2003) (4), pp. 237-246.

F. Abassi, J. Feyen and M.Th. van Genuchten, Two-dimensional simulation of water flow and solute transport below furrows: model calibration and validation, J. Hydrol. 290 (2004) (1-2), pp. 63-79.

J.G. Benjamin, L.K. Porter, H.R. Duke, L.R. Ahuja and G. Butters, Nitrogen movement with furrow irrigation method and fertiliser band placement, Soil Sci. Soc. Am. J. 62 (1998), pp. 1103-1108.

K.J. Beven, D. Henderson and A.D. Reeves, Dispersion parameters for undisturbed partially saturated soil, J. Hydrol. 143 (1993), pp. 19-43. 
Cote, C.M., Bristow, K.L., Ford, E.J., Verbug, K., Keating, B., 2001. Measurement of water and solute movement in large undisturbed soil cores: analysis of Macknade and Bundaberg data. CSIRO Land and Water, Technical Report 07/2001.

R.A. Feddes, P.J. Kowalik and H. Zaradny, Simulation of Field Water Use and Crop Yield, Simulation Monographs, Pudoc, Wagueninguen, The Netherlands (1978) 188 pp.

J.E. Fernandez, F. Moreno, F. Cabrera, J.M. Murillo and E. Fernandez, Water and nitrogen use efficiency in a maize crop in southern Spain, International Conference on Land and Water Resource Management in the Mediterranean Region, vol. I Inst. Mediter. Bari, Italy (1994).

M. Flury, H. Futler, W.A. Jury and I. Leuenberger, Susceptibility of soils to preferential flow of water: a field study, Water Resour. Res. 30 (1994), pp. 1945-1954.

Gonzalez, J.M., 1991. Modélisation stochastique d'une irrigation à la raie. Thèse de doctorat (PhD), Univ. Montpellier II, 222 pp. + annexes.

G.A. Lehrsch, R.E. Sojka and D.T. Westermann, Nitrogen placement, row, spacing, and furrow irrigation water positioning effects on corn yield, Agron. J. 92 (2000), pp. 1266-1275.

J.C. Mailhol and G. Gonzalez, Furrow irrigation model for real-time applications on cracking soils, J. Irrig. Drain. Eng. ASCE 119 (1993) (5), pp. 768-783.

J.C. Mailhol, M. Priol and M. Benali, A furrow irrigation model to improve irrigation practices in the Gharb valley of Morocco, Agric. Water Manage. 42 (1999), pp. 65-80.

Mailhol, J.C., 2001. Contribution à l'améloration des pratiques d'irrigation à la raie par une modélisation simplifiée à l'échelle de la parcelle et de la saison. Thèse de doctorat (PhD), Univ. Montpellier II, 276 pp. + annexes.

J.C. Mailhol, P. Ruelle and I. Nemeth, Impact of fertilisation practices on nitrogen leaching under irrigation, Irrig. Sci. 20 (2001), pp. 139-147.

J.C. Mailhol, A validation of a predictive form of Horton infiltration for simulating furrow irrigation, J. Irrig. Drain. Eng. ASCE 129 (2003), pp. 412-421.

B.k. Mishra and C. Misra, Nitrogen transformation during miscible displacement of ammonium nitrate solution through the root zone of maize, J. Ind. Soc. Soil Sci. 41 (1993), pp. 630-635.

Nemeth, I., 2001. Devenir de l'azote sous irrigation gravitaire. Application au cas d'un perimetre irrigué au Mexique. Thèse (PhD), Univ. Montpellier II, 205 pp. + annexes

D. Or, Wetting-induced soil structure changes. The theory of liquid phase sintering, Water Resour. Res. 2 (1996) (10), pp. 3041-3049.

N.A. Oyonarte, L. Mateos and M.J. Palomo, Infiltration variability in furrow irrigation, J. Irrig. Drain. Eng. 128 (2002) (1), pp. 26-33.

Popova, Z., Varlev, I., Kutev, V., Shopova, D., 2000. Lysimeter study on ground water degradation due to different fertilisation and irrigation management. In: Proceeding of ICIDICWRM in the 21st Century, Budapest, Hungary, 1-2 June 2000, pp. 177-181. 
S. Recous, C. Aita and B. Mary, In situ change in gross $\mathrm{N}$ transformation in bare soil after addition of straw, Soil Biol. Biochem. 31 (1994), pp. 119-133.

C.W. Robbins and D.L. Carter, Nitrate-nitrogen leached below the root zone during and following alfafa, J. Environ. Qual. 9 (1980), pp. 447-450.

J. Simunek, M. Sejna and M.Th. van Genuchten, The HYDRUS-1D and HYDRUS-2D codes for estimating unsaturated soil hydraulic and solutes transport parameters, Agron. Abstr. (1999), p. 357

M.Th. van Genuchten, A close-form equation for predicting the hydraulic conductivity of unsaturated soils, Soil Sci. Soc. Am. J. 44 (1980), pp. 892-898.

H. Vereecken, M. Vanclooster, M. Swerts and J. Diels, Simulating water and nitrogen behavior in soil cropped with wheat, Fert. Res. 27 (1991), pp. 233-243.

Zairi, A., Mailhol, J.C., Sltani, A., 1998. Water restriction impact on surface irrigation efficiency in cracking soil. In: First Inter Regional Conference on environment-water innovative issues in irrigation and drainage, Lisbon, 16-18 September 1988. 